\title{
Now is a Good Time to Recognize Teaching as Serious I ntellectual Work
}

\author{
Dan Bernstein, PhD \\ Professor, Department of Psychology \\ University of Kansas
}

In my work promoting changes in teaching that generate deeper understanding, I often meet colleagues who assert that good teaching is not valued in their institution. Their concern is that simple averages of a few student rating items drive all decisions about teaching, and the innovative work I recommend is not recognized as excellent instructional design and delivery. In response to that common perception, a community of faculty members has developed ways to represent excellent course design and evidence of enhanced understanding. Further, this community is working to identify and sustain an audience of peers who can offer substantive commentary on the scholarly quality of a faculty member's systematic inquiry into instruction and the learning it generates and supports. These ideas and practices have been developing for over 20 years, and they are available now as a complement to the typical student voice in the evaluation of teaching. Using them requires recognition that there is much more to effective higher education than knowledge of one's field and skill in communication and motivation. Given the current high level of expressed dissatisfaction with student ratings as the only indicator of teaching performance, we have an opportunity to move this conversation forward.

After 15 years on the faculty of the University of Nebraska - Lincoln (UN-L) I was discouraged that the tenure, promotion, and merit systems did not place much weight on the quality of teaching. There was certainly less than the nominal $40 \%$ allocation mentioned for teaching in public documents about faculty assignments. For several years in the late 1980s I worked with a group of faculty colleagues to raise this issue with department chairs and the deans they reported to. The major voice in the conversation about quality of teaching was that of students, mostly in the form of mandatory end-of-semester ratings of various aspects of their experience in a class. One dean told us that he would not make important decisions solely based on students' ratings, but he invited us to devise some additional indications of what we thought was excellence in teaching.

Around this time, many departments added a second voice to the tenure decision by asking an experienced faculty member to visit a class led by the tenure candidate. The observer followed up by writing a letter for the candidate's file describing what was observed and offering some kind of commentary or recommendation about the quality of the instruction. Many chairs, however, dismissed the significance of these peer reviews of classroom performance, mostly because they were almost universally positive about the teacher. Department committees and deans wanted some differentiation among tenure candidates on teaching, and the class-visitation letters rarely gave voice to any substantive information for the deliberations of the chair and the faculty committee.

National attention was brought to the conversation when the President of the Carnegie Foundation for the Advancement of Teaching offered a new vision of teaching in a book called Scholarship Reconsidered: Priorities of the Professoriate (Boyer, 1990). Boyer identified four equivalent forms of intellectual activity, and he suggested that each one merited being identified as scholarly activity. In this view, teaching was an activity in principle equal to the discovery or articulation of new knowledge, and therefore it should be accepted as evidence of scholarship in higher education personnel policies and practices. While sympathetic to this claim, I was skeptical about the analysis, fearing that this renaming of teaching would lead discovery scholars to call their work something else. In addition, my reading of the 
book did not provide a clear picture of how the students and the classroom observers would offer an informed opinion about the scholarship of teaching.

My colleagues and I moved ahead by generating a set of headings that prompted faculty colleagues to describe their own activities that they felt were innovative or particularly effective, along with attendance at workshops and conferences in which quality forms of teaching were presented, discussed, and even practiced. The answers to these prompts were included in the personnel file, providing the first opportunity for the faculty member's own voice to be part of the mix. Many departments adopted this prompt for voluntary descriptions, often adding an invitation for the faculty member to offer something loosely described as a teaching philosophy. At this point there were now three complementary voices in the conversation about teaching, although none of the voices seemed to offer a very strong or direct analysis of instructional quality.

In 1994 the American Association for Higher Education (AAHE) led 12 universities in implementation of peer collaboration and review of teaching that began to frame what a scholarship of teaching might look like (Hutchings, 1996). UN-L was one of those universities, and pairs of faculty members from our faculty teams began to exchange documents related to a course, along with a narrative about the design, implementation, and success of the course. Faculty members were asked to describe the following: (a) what their course was intended to achieve in students' understanding, (b) how their students' time and learning activities were directed toward that intellectual achievement, and (c) what they as instructors had learned about effective teaching by examining the students' performance on assignments intended to capture their understanding. These documents included a narrative account of what was done and a written reflection on how the whole process played out. At each of the three stages of this interaction, the faculty participants provided in writing their own course descriptions, and they also exchanged written feedback with their paired colleagues.

For the first time, those of us in the AAHE project experienced a format for providing a faculty voice that described an inquiry into students' learning. Instead of speaking about general course goals and describing one's own attitudes toward students, faculty members provided concrete and substantive examples of what they were doing to help students demonstrate a rich understanding of the material in the course. The project continued for three years, and over time each faculty member could write about a process of iterative innovation in learning activities that could be documented to show whether students' learning was increasing as a result. The comments written by a faculty peer might include observations during class time, but they were more focused on the process of enhancing the success of students in mastering the course goals. The peer voice in the conversation also took a big leap away from a general description of the climate in the class room and toward recognition of a serious inquiry into the best methods of helping students generate understanding of a field.

At this point we all felt we were finally making some progress in finding a suitable format for evaluation of teaching. The exchanged materials seemed like something that a dean would find credible, while the documents reported on collaborative activities that faculty members felt would help them become better teachers. Perhaps most important, many of us understood that excellent instructional design and continuous innovation in practices were a valuable form of intellectual inquiry. Our next goal was to find a clear way to represent that inquiry in a form that could be readily included in formal review of the quality of teaching.

A second book from the Carnegie Foundation titled Scholarship Assessed: Evaluation of the Professoriate (Glassick, Huber, \& Maeroff, 1997) greatly advanced our work toward developing a clear representation of intellectual inquiry. The book argued that all forms of scholarship have certain common characteristics, and so teaching could be a form of scholarship if it is conducted in a scholarly way. Those characteristics resulted from extensive interviews of academic scholars and leaders conducted by Mary Huber; as a cultural anthropologist, she sought our expectations 
of work we deem to be scholarly. The book suggests that scholarly work has six characteristics: (a) there are clear goals, (b) the scholar is aware of what others are doing, (c) the work is conducted using methods appropriate to the scholar's field, (d) the report includes significant results of the inquiry, (e) the work is made broadly available for comment, and (f) there is reflective critique of the work's meaning and implications. Simply teaching a course in a professionally competent way is a good idea, but that by itself does not result in scholarship. Identifying the full range of six characteristics put some concrete dimensions into Boyer's original call for a scholarship of teaching and learning.

For the next dozen years or so, many faculty members in the U.S. and throughout the English-speaking academic world developed ways to make inquiry into student learning a frequent feature of offering a course. While drawing heavily upon existing research and theory in higher education, some faculty members created communities within their own field of study that shared goals, assignments, assessments of student understanding, and a wide range of student-centered learning activities. When the reports included thoughtful reflection on the reasons for success and the remaining challenges, it was possible for peer readers to offer constructive and critical commentary aimed at furthering development of effective teaching. A range of local, national, and international organizations emerged to provide infrastructure for broad exchange of inquiry results and reflection. Communities of discipline-based scholarly inquiry thrived, and they facilitated the distribution of high-end knowledge about how to help students achieve deep understanding. Many scholarly societies established journals for reporting teaching activities and results (e.g., Teaching of Psychology, Journal of Management Education, Journal of College Science Teaching, College English), and organizations have appeared that support an explicitly scholarly approach to teaching (e.g., The International Society for the Scholarship of Teaching and Learning). The reports in these outlets, including as they did all of Huber's six dimensions of scholarship, emerged as a substantive body of work in the scholarship of teaching and learning.

Despite all of this activity, many (or even most) higher education institutions still rely primarily on student ratings of their experience, typically combined with some input from a classroom observer. The student voice is very important to the process of developing effective instruction, but only when it is used properly (Benton \& Ryalls, 2016). Students are good observers of classroom practice and can report some features of student-centered instructional design, but they should not be considered experts who can properly

Relatively few institutions ask faculty members to fully express their voice through documentation of goals, assignments, learning activities, and reflection on the development of quality learning in their courses over time. evaluate what they describe and put it in the context of research on education. In general students have no access to an independent account of how deeply their colleagues in general are learning and what percentage of students is achieving at high levels of understanding. Relatively few institutions ask faculty members to fully express their voice through documentation of goals, assignments, learning activities, and reflection on the development of quality learning in their courses over time. Accordingly, the peer voice is still typically limited to comments on a face-to-face session with students, as faculty members do not routinely provide their peers with rich accounts of the iterative development of effective instructional design. As a result, the peer voice contains little commentary or evaluation of the overall scholarly inquiry into how students can achieve greater understanding.

Why do I suggest that this is a good time to promote evaluation of teaching that explicitly considers the intellectual work in teaching? There is widespread dissatisfaction with the way teaching is currently evaluated, and many campuses are starting task forces to re-examine their processes and bring forward revisions or full reforms. The critiques come from many perspectives, ranging from statistical nuances (e.g., Stark \& Freishtat, 2014) to outright rejection of the 
student voice (e.g., Wieman, 2015). The student ratings systems are taking the brunt of the criticism, as their non-expert feedback lacks credibility with evaluators, regardless of the quality of the measures. Benton and Ryalls (2016) review the vast array of complaints, evaluating each with evidence and noting that ratings should never be used alone as a source of evaluation. Given the disruption created by uncertainty about the quality of current practice, this is a great opportunity for those faculty members who are actively engaged in many forms of the scholarship of teaching and learning to request that their work be explicitly invited into the routine evaluation procedures on their campuses. There is a vacuum at the center of this important conversation and now there are many, many fine examples of scholarly teaching that can be offered to fill that vacuum. In the past 20 years we have seen exponential growth in venues for sharing SoTL work in ways that meet the six characteristics of scholarship. There are conferences on teaching in most disciplines, there are journals that share this work broadly, and there are websites that host portfolios of iterative inquiry into student understanding. We just need to ask (or even insist) that the eyes and minds of evaluators be focused on this intellectual work as an essential complement to the existing student voice.

This critical moment in evaluating teaching also provides a great opportunity for us to advance the peer voice beyond its role as an observer of inclass performance. For those who want a formal peer review of the intellectual quality of the work, there are formats for internal and external review that can be readily adapted for use in local personnel processes (Bernstein, 2008; Bernstein et al., 2010; Bernstein, Burnett, Goodburn, \& Savory, 2006). Organized materials in online portfolios (e.g., KU Center for Teaching Excellence Portfolio Gallery) also provide a powerful format for representation that complements the usual publication outlets, and those materials are easily exported to local colleagues for review. In cases of major personnel activities, the materials and questions for external reviewers to address are already well developed (e.g., Bernstein et al., 2010; Bernstein et al., 2006).

In many institutions the role of external review has been served by conventional publication outlets such as InSight or Teaching and Learning Inquiry, an interdisciplinary journal produced by the International Society for the Scholarship of Teaching and Learning. These outlets include expert peer evaluation of the intellectual quality of the work, so they come with established credibility as a research enterprise. Speaking through those outlets requires substantial analysis and reporting skill, plus learning the conventions of an additional publication community. Some faculty members have sufficient time and other resources to develop a second research life in that depth, but not everyone has those resources or even wants to communicate in that way. Treating teaching as a research and publication enterprise adds additional activities that will compete with the time for teaching itself. Whether faculty members have a large number of teaching assignments and/or substantial expectations of "regular" research productivity, I have found that adding an expectation of publication is rarely welcomed.

In a previous essay (Bernstein, 2010) I suggested that individual faculty members can find different paths within the SoTL world and not everyone needs to treat this work as research. Many of us have developed venues for sharing and reviewing systematic inquiry into teaching and learning without arguing that it needs to have all the trappings of a research program. Instead we suggest that our institutions honor real excellence in teaching because it is important in its own right and very difficult to do well, not because we enter into a research community. Excellent teaching is more than simply delivering a competent course that students experience as useful. We need to promote meaningful peer review of the intellectual inquiry done by faculty members as an inherent characteristic of excellent teaching.

It is important to acknowledge that more time will be spent providing meaningful representation of intellectual work and generating substantive peer review of that form of teaching than is now devoted to evaluating teaching. Simply 
collecting student ratings reports requires zero faculty time, so even a relatively small amount of time will seem like a change in the wrong direction. Even though the additional time is less than what is required to publish educational research, it is still some more time. When that issue is raised it is important to remind colleagues that they already invest a huge amount of time in designing, preparing, delivering, and evaluating the learning in every class they teach. The amount of time required to capture that work and reflect on its success is a very small number of hours in comparison with the entire effort; the marginal cost of this work beyond the initial investment of time and intellectual energy is very reasonable. It should also be remembered that no one suggests that every course should be looked at in this detail every semester. The models we have proposed in several contexts (e.g., Bernstein et al., 2010) call for a faculty member to document and reflect on only one or two courses over a period of five years, perhaps tracking progress in learning in the same course over two or three offerings. That should be the new face of the faculty member's voice in evaluation of teaching.

It is also worth mentioning that many faculty members happily give time to reviewing the intellectual work found in submitted articles and proposed books or chapters prior to their publication; people often list those invited reviews in personnel reports as evidence of their own expertise. It would be a harsh statement of the relative value of teaching and research to claim that reviewing research is worthwhile but reviewing teaching is not worth the time. It is time for us to assert that reviews of all forms of serious intellectual work are of great value to our institutions, and we need to honor that work as important professional service that can be recognized and rewarded. The time needed to review peers' teaching for promotion or tenure should not be accepted as a barrier to this improvement in practice, as the products of these reviews will constitute a new and more substantive peer voice in the evaluation of teaching. No one would evaluate a biologist by watching her work in the lab, but we review her teaching by watching her in class for an hour. It will be a much richer peer voice when a reviewer looks over a portfolio with course materials, student work, and the instructor's narrative of inquiry over time. Our experience in working on peer review also indicates that reviewers find this work much more interesting and satisfying than sitting in a class.

This journey began when some faculty members asked academic leaders why teaching was not valued in the personnel system. Beyond the values of institutional missions, an important reason was the absence of credible evidence of excellence. Without clear demonstration that teaching was informed, effective, and connected with scholarly work on education, it would be difficult to make important decisions. The path toward current representations of inquiry into learning took a

\section{Since our whole profession seems deeply interested in finding a better way to evaluate our teaching, this is a great opportunity to bring forward the emerging work in many forms of the scholarship of teaching and learning.} quality inquiry into students' understanding. Since our whole profession seems deeply interested in finding a better way to evaluate our teaching, this is a great opportunity to bring forward the emerging work in many forms of the scholarship of teaching and learning. At the very least this work needs to be welcome in the processes of our institutions, and perhaps we can argue that true excellence cannot be demonstrated by merely delivering competent instruction. It would be a huge step forward if we can raise the bar for excellence to mean sustained inquiry into effective teaching that generates student understanding. Now is a very good time to take steps toward such a goal by reframing the faculty and peer voices in the intellectual work in teaching. 


\section{References}

Benton, S. L., \& Ryalls, K. R. (2016). IDEA Paper No. 58: Challenging misconceptions about student ratings of instruction. Manhattan, KS: The IDEA Center. Retrieved from http://ideaedu.org/wp-content/uploads/ 2016/04/PaperIDEA_58.pdf

Bernstein, D. (2010). Finding your place in the scholarship of teaching and learning. International Journal for the Scholarship of Teaching and Learning, 4(2), $4 . \quad$ doi: 10.20429/ijsotl.2010.040204

Bernstein, D., Addison, W., Altman, C., Hollister, D., Komarraju, M., Prieto, L., ... Shore, C. (2010). Toward a scientisteducator model of teaching psychology. In D. F. Halpern (Ed.), Undergraduate education in psychology: A blueprint for the future of the discipline (pp. 29-45). Washington, DC: American Psychological Association.

Bernstein, D., Burnett, A. N., Goodburn, A., \& Savory, P. (2006). Making teaching and learning visible: Course portfolios and the peer review of teaching. Bolton, MA: Anker.
Bernstein, D. J. (2008). Peer review and evaluation of the intellectual work of teaching. Change: The Magazine of Higher Learning, 40(2), 48-51. doi: 10.3200/CHNG.40.2.48-51

Boyer, E. L. (1990). Scholarship reconsidered: Priorities of the professoriate. Princeton, NJ: The Carnegie Foundation for the Advancement of Teaching.

Glassick, C. E., Huber, M. T., \& Maeroff, G. I. (1997). Scholarship assessed: Evaluation of the professoriate. San Francisco, CA: Jossey-Bass.

Hutchings, P. (1996). Making teaching community property: A menu for peer collaboration and peer review. Washington, DC: American Association for Higher Education.

Stark, P. B., \& Freishtat, R. (2014). An evaluation of course evaluations. ScienceOpen. doi: 10.14293/S21991006.1.SOR-EDU.AOFRQA.v1

Wieman, C. (2015). A better way to evaluate undergraduate teaching. Change: The Magazine of Higher Learning, 47(1), 6-15. doi: 10.1080/00091383.2015.996077

Dan Bernstein is Professor Emeritus of Psychology at the University of Kansas and former Director of its Center for Teaching Excellence (2002-2014). His writing has focused on electronic course portfolios centered on student learning, and he helps colleagues showcase their teaching practices that yield high quality student work. Recent grants from the Teagle and Spencer Foundations have developed teamdesigned assignments and scaffolding, explored the use of assessment data in curriculum change, and promoted interactive learning in humanities instruction. Previous grants supported substantive peer review of the intellectual work in teaching, resulting in a 2006 book entitled Making Teaching and Learning Visible. His ongoing courses are a laboratory for evaluating web-based learning activities. He was a Charter Member of the University of Nebraska Academy of Distinguished Teachers and a Carnegie Scholar in 1998. He received the Fred S. Keller Behavioral Education Award from Div. 25 of the American Psychological Association, and he is a past President of the International Society for the Scholarship of Teaching and Learning and of the Society for the Experimental Analysis of Behavior. 